\title{
Differential Response of the Epithelium and Interstitium in Developing Human Fetal Lung Explants to Hyperoxia
}

\author{
PORUS BUSTANI, RACHEL HODGE, ANANTH TELLABATI, JUAN LI, HITESH PANDYA, AND SAILESH KOTECHA
}

Division of Child Health, University of Leicester, Leicester LE2 7LX, United Kingdom

\begin{abstract}
Hyperoxia is closely linked with the development of chronic lung disease of prematurity (CLD), but the exact mechanisms whereby hyperoxia alters the lung architecture in the developing lung remain largely unknown. We developed a fetal human lung organ culture model to investigate (a) the morphologic changes induced by hyperoxia and (b) whether hyperoxia resulted in differential cellular responses in the epithelium and interstitium. The effects of hyperoxia on lung morphometry were analyzed using computer-assisted image analysis. The lung architecture remained largely unchanged in normoxia lasting as long as $4 \mathrm{~d}$. In contrast, hyperoxic culture of pseudoglandular fetal lungs resulted in significant dilatation of airways, thinning of the epithelium, and regression of the interstitium including the pulmonary vasculature. Although there were no significant differences in Ki67 between normoxic and hyperoxic lungs, activated caspase-3 was significantly increased in interstitial cells, but not epithelial cells, under hyperoxic conditions. These changes show that exposure of pseudoglandular lungs to hyperoxia modulates the lung architecture to resemble saccular lungs. (Pediatr Res 59: 383-388, 2006)
\end{abstract}

$\mathrm{T}$ The clinical spectrum of CLD varies from children with oxygen dependency with poorly reversible airway disease to those with a mild degree of hypoxemia in air but who develop wheezing with respiratory tract infections (1). Functional abnormalities associated with CLD are secondary to abnormal postnatal alveolar development $(2,3)$, possibly mediated via pulmonary inflammation (4-6). Thus, understanding the pathophysiologic mechanisms leading to abnormal alveolar development in developing preterm lungs has important therapeutic implications.

CLD is closely linked with oxygen dependency and with dysregulated lung growth (7). The mechanisms whereby oxygen results in abnormal lung growth remain to be defined. Human studies, animal models of CLD, and cell culture systems have shown that the effects of hyperoxia on developing lungs are partly mediated by increased generation of reactive oxygen species $(\mathrm{ROS})(8,9)$ and that hyperoxia has a differential action on pulmonary cell growth. Depending largely on ontogeny, some cell types proliferate, whereas others undergo mitotic arrest or die in response to oxidative

Received March 10, 2005; accepted September 29, 2005.

Correspondence: Sailesh Kotecha, Ph.D., Department of Child Health, Cardiff University, Cardiff CF14 4XN, UK; e-mail: KotechaS@cardiff.ac.uk.

The project was funded by departmental funds.

DOI: 10.1203/01.pdr.0000198774.79043.5c stress $(10,11)$. Thus, hyperoxia may alter pulmonary development and structure by differentially modulating the fate of pulmonary cells.

Normal lung growth is regulated at a number of levels. Factors such as epithelium-mesenchyme interactions coordinate and regulate lung development by modulating the proliferation, differentiation, or apoptosis of pulmonary cells (1214). Thus, given the effects of oxygen and ROS on pulmonary cell function and fate, we hypothesized that hyperoxia causes maldevelopment of lung growth by disrupting the pattern of pulmonary cell growth associated with normal lung development. Specifically, we developed a fetal human lung organ culture model to investigate (a) the morphologic changes induced by hyperoxia and (b) whether hyperoxia resulted in differential cellular responses in the epithelium and interstitium.

\section{METHODS}

Tissue culture. Pseudoglandular stage human lungs of 10 to 18 wk of gestation were obtained from the Medical Research Council Tissue Bank, London, UK, and the study was approved by the local research ethics committee. The lungs were dissected into wedge-shaped $\left(2-3 \mathrm{~mm}^{3}\right)$ pieces and embedded in gel-forming medium $(300 \mu \mathrm{L})$ consisting of fetal bovine serum ( $1 \mathrm{~mL}$, Sigma Chemical Co. Aldrich, Poole, UK), 7.5\% $\mathrm{NaHCO}_{3}(0.33$ $\mathrm{mL}), 5 \times$ Ham's F12 $(2 \mathrm{~mL}), 0.1 \mathrm{~mol} / \mathrm{L} \mathrm{CaCl} 2(0.1 \mathrm{~mL}), 1 \mathrm{mmol} / \mathrm{L} \mathrm{N}-2-$ hydroxyethylpiperazine- $N^{\prime}$-2-ethanesulfonic acid (HEPES, $0.1 \mathrm{~mL}$ ), $1 \mathrm{~mol} / \mathrm{L}$ $\mathrm{HCl}(0.1 \mathrm{~mL}), \mathrm{H}_{2} \mathrm{O}(3.5 \mathrm{~mL})$, and $3 \mathrm{~mL}$ Vitrogen (Collagen Corp, Palo Alto, CA) at $\mathrm{pH} 7.4$ (15) to produce $10 \mathrm{~mL}$ of fresh solution. Embedded lung explants were cultured in $2 \mathrm{~mL}$ of organ culture medium in a $5 \% \mathrm{CO}_{2} / \mathrm{ambient}$ air, humidified incubator at $37^{\circ} \mathrm{C}$. The organ culture medium consisted of: Ham's F12 with $25 \mathrm{mmol} / \mathrm{L}$ HEPES $(88 \mathrm{~mL})$, penicillin $(10,000 \mathrm{U} / \mathrm{mL})$ and streptomycin $(10,000 \mu \mathrm{g} / \mathrm{mL})$ solution $(1 \mathrm{~mL})$, glutamate $200 \mathrm{mmol} / \mathrm{L}(1$ $\mathrm{mL}), 1 \mathrm{~mol} / \mathrm{L} \mathrm{NaOH}(0.16 \mathrm{~mL})$, and fetal bovine serum $(10 \mathrm{~mL})$ at $\mathrm{pH} 7.4$. After $24 \mathrm{~h}(\mathrm{~d} 1),>90 \%$ of fetal lung explants were deemed viable because they showed evidence of cell migration into the surrounding matrix. Two randomly selected viable explants were harvested at this stage for immunohistochemistry.

Exposure of explants to hyperoxia. The culture medium was replaced with fresh medium in the remaining viable explants, which were randomly assigned to either $5 \% \mathrm{CO}_{2} /$ ambient air incubator (Normoxia) or in humidified airtight jars (Oxoid, Basingstoke, UK) gassed with a $5 \% \mathrm{CO}_{2} / 95 \% \mathrm{O}_{2}$ gas mixture for $10 \mathrm{~min}$ at $10 \mathrm{~L} / \mathrm{min}$ (hyperoxia). The gassed airtight jars were maintained at $37^{\circ} \mathrm{C}$ in a temperature-controlled incubator; internal environment was maintained for as long as $72 \mathrm{~h}$ in preliminary experiments (11). At least one explant was harvested for immunohistochemistry at 48 and $72 \mathrm{~h}$ of

Abbreviations: CLD, chronic lung disease of prematurity; D1, fetal lung explants cultured for $24 \mathrm{~h}$ before exposure to either hyperoxia or normoxia; H48, fetal lung explants exposed to hyperoxia for $48 \mathrm{~h}$; H72, fetal lung explants exposed to hyperoxia for $72 \mathrm{~h}$; $\mathbf{N 4 8}$, fetal lung explants exposed to normoxia for $48 \mathrm{~h}$; N72, fetal lung explants exposed to normoxia for $72 \mathrm{~h}$; ROS, reactive oxygen species; VEGF, vascular endothelial growth factor 
culture in normoxia (N48, N72) or hyperoxia (H48, H72), fixed in $4 \%$ formaldehyde, and embedded in wax paraffin. Further explants were snap frozen at $24 \mathrm{~h}$ for vascular endothelial growth factor (VEGF) mRNA detection.

Immunohistochemistry. Wax-embedded explants were used for immunostaining and image analysis. Serial sections (4 $\mu \mathrm{m}$ thick) were deparaffinized, and antigens retrieved by boiling in a pressure cooker for $4 \mathrm{~min}$ in $10 \mathrm{mmol} / \mathrm{L}$ citric acid solution ( $\mathrm{pH}$ 6.0). Subsequently, the sections were treated with $0.3 \% \mathrm{H}_{2} \mathrm{O}_{2}$ in methanol, nonspecific binding sites were blocked (Serum-free Protein Block, Dako, Carpinteria, CA) and incubated overnight at $4^{\circ} \mathrm{C}$ in $0.05 \%$ bovine serum albumen/phosphate-buffered saline (PBS) solution with one primary antibody: anti-pancytokeratin (1:200 dilution, Sigma Chemical Co., Aldrich, Poole, UK), anti-CD31 (1:30, cloneJC/70A, Dako), anti-Ki67 (1:100, Pharmingen, San Diego, CA), or anti-activated caspase-3 (1:500, R\&D Systems, Oxon, UK). Sections were then incubated with a biotinylated secondary antibody, goat anti-mouse (1:200, Dako), or goat antirabbit (1:400, Sigma Chemical Co.) as appropriate. The antigen of interest was visualized by using the brown chromogen 3,3'-diaminobenzidine. The sections were washed with PBS between each step.

Analysis of fetal lung explant architecture. Mid-depth sections from tissues were examined to ensure comparability between lung explants. All sections were coded to ensure a blind analysis. The sections stained with pancytokeratin were digitally photographed in their entirety at low magnification $(\times 40)$. Image analysis software was used to measure the total surface area of the section, and the surface area of each individual airway within the section. Using these measurements, the mean airway surface area, the number of airways per unit area and the proportion of the section occupied by airways for each section were derived. High-power digital images from randomly selected fields were used to determine the mean thickness of epithelial cells lining the airways.

Lung sections immunostained with anti-CD31, anti-Ki67, and antiactivated caspase- 3 were used to identify endothelial, proliferating, and apoptotic cells, respectively. For each stain, one section was used per time point for a given lung. For each section, eight high-power $(\times 400)$ digital images were obtained circumferentially at set intervals to prevent unbiased sampling and to allow comparisons of images at similar distances from the surface of the tissue. The images were analyzed to determine (a) the surface area occupied by blood vessels, (b) the mean distance from blood vessels to nearest airway lumen, and (c) the proportion of cells staining positively for Ki67 and activated caspase- 3 in total tissue and in the epithelial and interstitial compartments. Cells detached from the airway lining or with unrecognizable morphology staining positively for anti-activated caspase-3 were excluded from analysis.

The data are shown as median \pm interquartile ranges. The nonparametric test Wilcoxon signed rank test was used to compare normoxia (N72) and hyperoxia (H72) for $72 \mathrm{~h}$, and multiple comparisons were made by using the nonparametric test, Kruskal-Wallis; $p<0.05$ was considered significant.

Detection of VEGF $\boldsymbol{m R N A}$. VEGF mRNA was detected by reverse transcriptase polymerase chain reaction (RT-PCR) as previously described in three fetal lung explants cultured in normoxia and hyperoxia for $24 \mathrm{~h}$ (16). To enable comparison between experiments, normoxia was designated $100 \%$ in each experiment and the relative intensity is shown for VEGF mRNA detected in explants exposed to hyperoxia. $\beta$-actin mRNA was shown to be similarly expressed in all experiments.

\section{RESULTS}

Morphologic changes associated with hyperoxia. The microscopic appearance of $\mathrm{d} 1$ fetal lung tissue was similar to pseudoglandular stage lung tissue, showing large numbers of columnar, epithelium-lined, tubular air spaces, branching and developing alongside pulmonary blood vessels in an overall framework of poorly differentiated interstitium (Fig. 1A). Explants cultured in normoxia for a further $72 \mathrm{~h}$ appeared similar to $\mathrm{d} 1$ cultures and freshly isolated pseudoglandular tissue, except that some peripheral airways were dilated and the epithelium was more cuboidal (Fig. 1B). In the hyperoxiaexposed lungs, the airways were much larger and the epithelial cells appeared flattened within the dilated airways when compared with normoxia-exposed tissue (Fig. 1C). The blood vessels stained with CD31 in the normoxia-exposed explants had a plexiform appearance, similar to the vascular morphol-
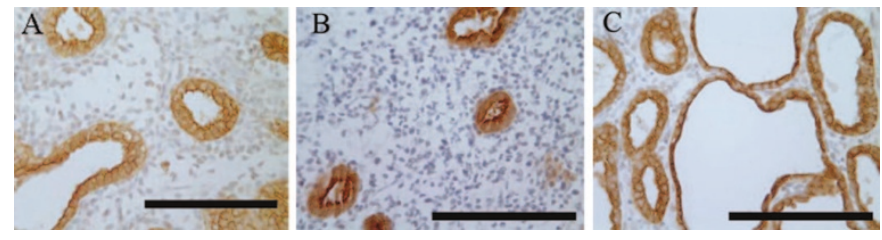

Figure 1. Representative immunostained sections of cultured lung explants. (A) Cytokeratin labeling of tissue after 24-h initial culture showed typical pseudoglandular appearance with columnar cells and small airways. Subsequent culture for a further $72 \mathrm{~h}$ in normoxia maintained overall structure but with a more cuboidal epithelium $(B)$, whereas culture in hyperoxia for the same period resulted in larger airways, thinner epithelium, and less interstitium $(C)$. Bars represent $100 \mu \mathrm{m}$.

ogy of pseudoglandular uncultured tissue (Fig. 2A). In contrast, there was a decreased number of vessels in hyperoxiaexposed explants, and where they were present, the vessels were linear, lining the dilated airways (Fig. 2B).

Image analysis of lung explants exposed to hyperoxia. Morphometric analysis was performed on six complete experiments. The cross-sectional surface area of the airways was largely similar to that of the explants cultured for up to $72 \mathrm{~h}$ in normoxia and day 1 tissues (Fig. 3A). This is more clearly shown in Figure $3 B$, which shows the cumulative airway size pooled for all lungs studied. In contrast, the median airway cross-sectional area of the explants exposed to hyperoxia was increased at $48 \mathrm{~h}$ and was further increased at $72 \mathrm{~h}$ (all $p<$ 0.05 when hyperoxic tissue compared with corresponding normoxic tissue or d 1 samples) (Fig. $3 A$ ). These enlarged airways in the hyperoxic explants at $72 \mathrm{~h}$ were lined with thinner epithelial walls [mean epithelial thickness $6.4 \mu \mathrm{m}$ [interquartile range (IQR), 6-7] relative to the corresponding normoxic tissue $[8.7 \mu \mathrm{m}(\mathrm{IQR}, 8-10)](p<0.05)$. The number of airways per surface area was similar in tissue exposed to normoxia and hyperoxia at $72 \mathrm{~h}$ of culture [N72

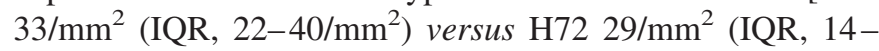
$\left.38 / \mathrm{mm}^{2}\right), p=$ not significant (NS)], thus suggesting the increased surface area was not due to increased airway numbers.

The interstitium occupied a similar proportion of the section surface area at d 1 [median, $85 \%$ (IQR, 84-87\%)] and in normoxic tissue at $48 \mathrm{~h}[85 \%$ (IQR, 79-86\%)] and $72 \mathrm{~h}[85 \%$ (IQR, 77-88\%)]. However, this proportion decreased significantly in the hyperoxic tissue [63\% (IQR, 48-75\%) at $48 \mathrm{~h}$ and $57 \%$ (IQR, $52-76 \%$ ) at $72 \mathrm{~h}], p<0.05$, when compared with $\mathrm{d} 1$ and corresponding normoxic tissue. We counted the number of epithelial and interstitial cells in eight high-power

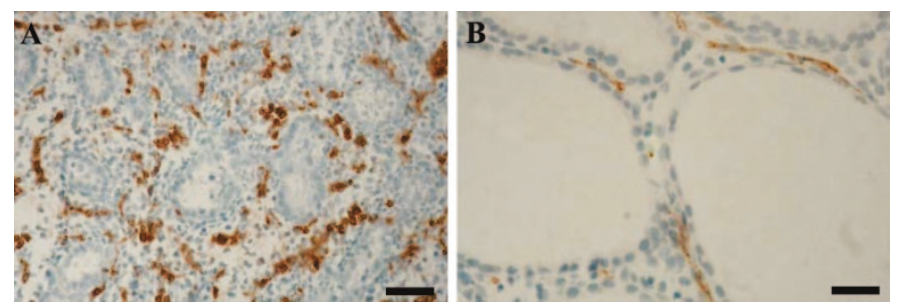

Figure 2. Staining of vasculature with $\mathrm{CD} 31$ in cultured lung. Normoxic tissue $(A)$ showed small bundles of vascular tissue within the interstitium. In hyperoxic cultured tissue $(B)$, the vessels regressed and were more linear. Bars represent $20 \mu \mathrm{m}$. 

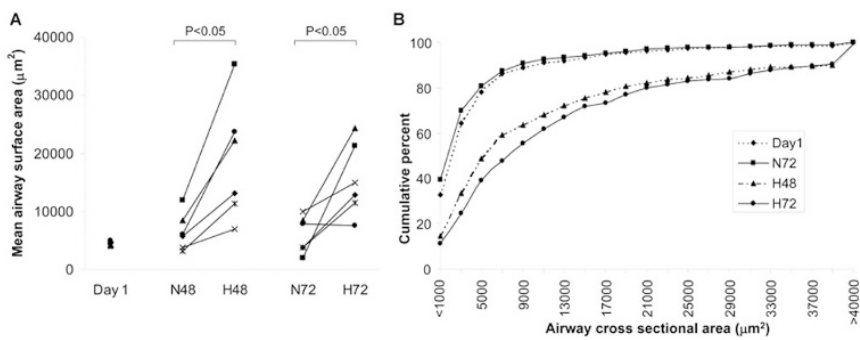

Figure 3. (A) Mean airway surface area is increased in hyperoxic conditions compared with normoxia at 48 and $72 \mathrm{~h}$. The lines $(n=6)$ depict changes that occurred in explants from the same lung exposed to either normoxia or hyperoxia. Significant differences were noted between the normoxic and hyperoxic at both 48 and $72 \mathrm{~h}$ (both $p<0.05$ ). (B) Cumulating curves depicting distribution of relative airway sizes demonstrated similar airways in d 1 tissue and normoxia-cultured (N72) tissue. Culture in hyperoxic conditions (H48 and H72) resulted in a predominance of larger airways.

fields on each section. The relative contribution by interstitial cells was similar in the $\mathrm{d} 1$ [median, 70\% (IQR, 69-75\%)] and normoxic tissues at $72 \mathrm{~h}[71 \%$ (IQR, 66-74\%)]. In contrast, the hyperoxia-exposed tissues were composed of a lower percentage of interstitial cells [62\% (IQR, 54-67\%); $p<0.05$ when compared with d 1 and N72 conditions].

Vasculature changes associated with hyperoxic exposure of fetal lung explants. We explored whether the reduced interstitium was accompanied by vasculature changes. The proportion of interstitium staining positive for CD31 was 7\% (IQR, 5-8\%) in normoxic tissue at $72 \mathrm{~h}$, but this difference was not significant when compared with d 1 samples [3.4\% (IQR, 3.0-6.6\%)]. In the hyperoxic tissue at $72 \mathrm{~h}$, the blood vessels were more closely located near the airway lumen (25 $\mu \mathrm{m}$ (IQR, 21-30 $\mu \mathrm{m}$ ) than in the $\mathrm{d} 1$ (37 $\mu \mathrm{m}$ (IQR, 34-39 $\mu \mathrm{m}) ; p<0.05]$ or normoxic explants after $72 \mathrm{~h}$ of culture (35 $\mu \mathrm{m}$ (IQR, $32-38 \mu \mathrm{m}) ; p<0.05]$. The vasculature comprised less of the interstitium in the hyperoxic tissue when compared with the corresponding normoxic tissue [median H72, 4\% (IQR, 2.3-5.3\%) versus median N72, 7\% (IQR, 5-8\%); $p<$ 0.05]. VEGF mRNA determined in three explants by RT-PCR was decreased in explants exposed to hyperoxia when compared with normoxia-exposed explants (Fig. 4).

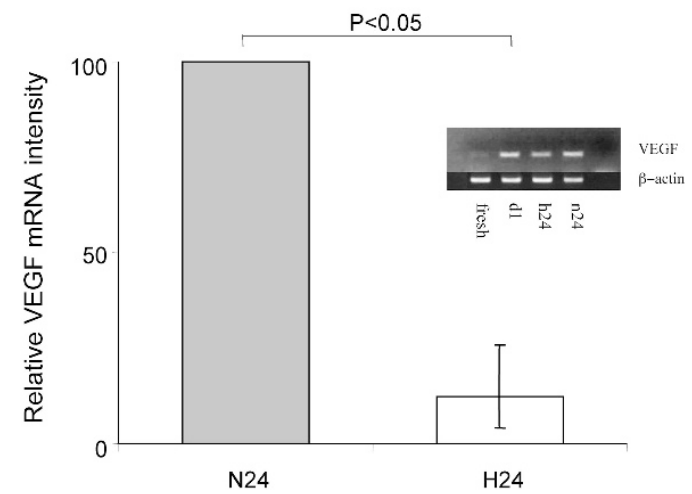

Figure 4. A significant decrease $(p<0.05)$ in VEGF mRNA was noted when explants $(n=3)$ were exposed to hyperoxia for $24 \mathrm{~h}(\mathrm{H} 24)$ when compared with those explants exposed to normoxia for $24 \mathrm{~h}$ (N24). Inset shows representative explant amplified for VEGF mRNA by RT-PCR.
Cell proliferation and apoptosis indices in cultured fetal lung explants. The nuclear antigen Ki67 was used to determine the cell proliferation index $(n=6)$. Positively staining cells were noted in both epithelium and interstitium in $\mathrm{d} 1$ samples (Fig. 5A). In contrast, normoxia- and hyperoxiacultured tissue appeared to have less positive staining for Ki67 in the interstitium (Fig. $5 B$ and $C$ ). The proportion of Ki67 immunoreactive cells was higher in d 1 explants [12\% (IQR, $9-15 \%)]$ than in explants maintained in culture for a further $72 \mathrm{~h}$ in either normoxia [5\% (IQR, 4.5-8.0\%)] or hyperoxia [8\% (IQR, 5-11\%); $p<0.05$ for d 1 versus $\mathrm{N} 72$ and for $\mathrm{d} 1$ versus $\mathrm{H} 72$ (Fig. 6]. This difference was mainly due a greater proportion of Ki67-positive cells in the interstitial cell compartment of d 1 explants [d 1, 12\% (IQR, 9-13\%); N72, 4\% (IQR, 2.4-5.2\%) and H72, 3\% (IQR, 1.9-3.8\%); $p<0.05$ for $\mathrm{d} 1$ versus $\mathrm{N} 72$ and for $\mathrm{d} 1$ versus $\mathrm{H} 72]$. The proportion of Ki67-positive cells in the epithelial compartment was similar for all conditions [d 1, 13\% (IQR, 9-16\%); N72, 10\% (IQR, $4-16 \%$ ) and $\mathrm{H} 72,13 \%$ (IQR, 10-16\%)].

The cell apoptosis index was determined by staining for activated caspase-3 $(n=6)$. Activated caspase-3-positive cells were found mostly in the interstitium (Fig. 7). Significantly more positive staining was noted in the hyperoxic tissues in the interstitium with the least staining observed on $\mathrm{d}$ 1. This was confirmed on quantitative analysis: the proportion of activated caspase-3-positive cells was lowest on d 1 [2\% (IQR, 1.6-4.8\%)] and highest in hyperoxic explants [N72: 4.3\% (IQR, 4.0-4.6\%); H72: 9\% (IQR, 5.0-12\%), $p<0.05$ for $\mathrm{H} 72$ versus $\mathrm{d} 1$ ); Fig. 8]. This difference was largely due a greater proportion of activated caspase-3-positive cells in the interstitial compartment of hyperoxia-exposed fetal lung explants [d $1=3 \%$ (IQR, 2.0-5.5\%), N72 = 4.3\% (IQR, $4.0-4.6 \%)$ and $\mathrm{H} 72=11 \%$ (IQR, $7-15 \%) ;(p<0.05$ for $\mathrm{H} 72$ versus $\mathrm{d} 1$ and $p<0.05$ for $\mathrm{H} 72$ versus $\mathrm{N} 72)$ ]. The apoptosis index in the epithelial compartment was similar in all conditions (d 1: 1\% (IQR, 0.5-2.7\%), N72: 5\% (IQR, 3.9-5.6\%), and $\mathrm{H} 72: 2 \%$ (IQR, $1.3-2.9 \%$ ); $p=\mathrm{NS}$ ].

\section{DISCUSSION}

The main observation of this study is that environmental $\mathrm{Po}_{2}$ modulates the growth of pseudoglandular stage fetal human lung explants maintained in submersion culture by differentially modulating the growth of pulmonary cells. Between 7 and $17 \mathrm{wk}$ of gestation (pseudoglandular stage), fetal lungs have a glandular appearance and seem to grow in size
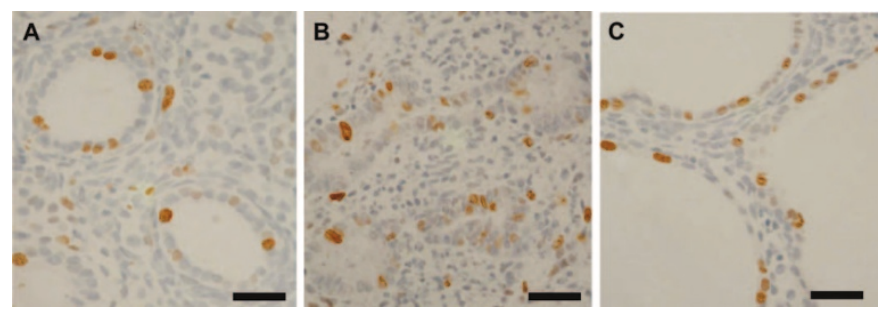

Figure 5. Tissue stained for Ki67 showed proliferating cells in both epithelium and interstitium in $\mathrm{d} 1$ explants $(A)$. In contrast, normoxia $(B)$ and hyperoxia $(C)$ cultured tissue had positive cells predominantly in the epithelium. Bars represent $20 \mu \mathrm{m}$. 


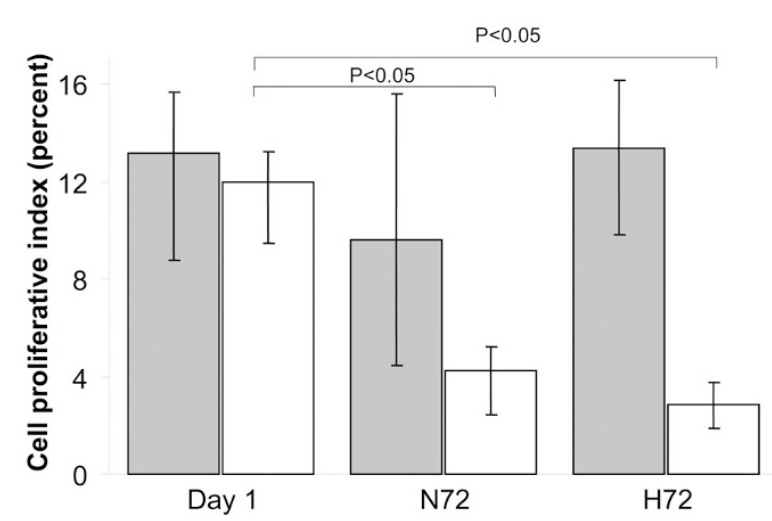

Figure 6. Epithelial cell (shaded columns) proliferation rates were relatively unaffected by culture (N72) or hyperoxia (H72) when compared with d 1 tissue. Interstitial cell (open columns) proliferation decreased in N72 and H72 tissue when compared with $\mathrm{d} 1$ tissue $(p<0.05)$. $(n=6)$. IQRs are shown.

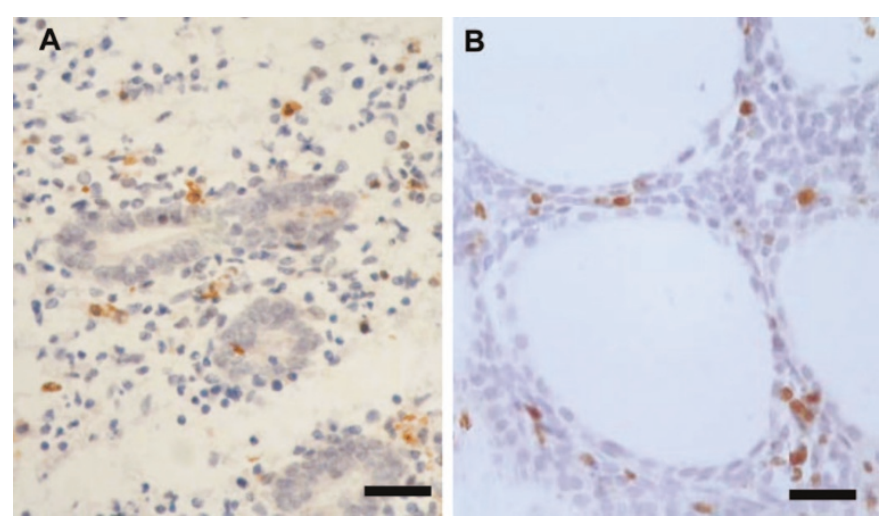

Figure 7. Tissue stained for activated caspase- 3 showed occasional apoptotic cells in the interstitium and epithelium in normoxic cultured tissue (N72) (A). Hyperoxia cultured tissue (H72) had numerous apoptotic cells within the interstitium (B). Bars represent $20 \mu \mathrm{m}$.

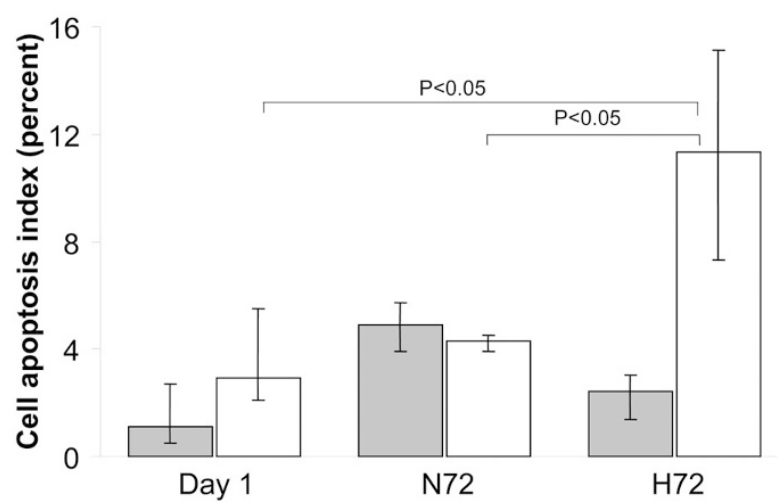

Figure 8. Epithelial (shaded columns) apoptosis was unaffected by culture in normoxia (N72) or hyperoxia (H72). Interstitial (open columns) apoptosis was increased in N72 tissue when compared with d 1 tissue. H72 interstitium demonstrated a further increase in apoptosis $(p<0.05)$. $(n=6)$. IQRs are shown.

largely through an increase in cell mass. Their growth is characterized by repeated branching of small-caliber airways within a framework of poorly differentiated interstitium (7), which also supports the development of pulmonary blood vessels. Except for dilatation of some airways at the edge of explants, the architecture of fetal lung explants placed in culture for $72 \mathrm{~h}$ at ambient air $\mathrm{Po}_{2}$ appeared similar to uncultured pseudoglandular stage pulmonary tissue.

In contrast, fetal lung explants cultured for $72 \mathrm{~h}$ at $\sim 95 \mathrm{kPa}$ $\mathrm{Po}_{2}$ resembled saccular stage more than pseudoglandular stage lung architecture. In hyperoxia-exposed fetal lung explants, the air spaces were dilated, the epithelium was flattened, and the surface area of the interstitial compartment was decreased. There was also a pronounced reduction in blood vessel volume and a significantly decreased distance between the airways and pulmonary blood vessels. These observations were not due to an increased number of airways per surface area in the hyperoxic tissues.

Oxygen modulation of cultured fetal lung architecture is likely to involve the same processes that modulate normal lung development such as cellular apoptosis, proliferation, differentiation, and changes in cell function. The significantly decreased interstitial compartment in hyperoxia-exposed explants may be explained by the higher apoptotic index in the interstitial cells in hyperoxia-exposed tissue because the proliferation index in this compartment was similar in the air- and oxygen-exposed tissues. As might be expected, dilatation of airways in hyperoxia-exposed tissue was associated with an increase surface area of the airway epithelial cell compartment. However, changes in cell proliferation and apoptosis may only partly account for the increased surface area of the epithelial cell compartment in hyperoxic explants. Another possible explanation is an increase in the actual size of the epithelial cells. The airway epithelium differentiated from columnar in d 1 explants to cuboidal in N72 explants and to flattened cells in hyperoxia-exposed airways. Explant culture has previously been shown to result in accelerated maturation of the epithelium to type II pneumocytes (17), and the change to cuboidal morphology in the normoxic explants reflects this change. The further thinning of the cells to hyperoxia is analogous to development of type I cells, which are known to have a greater surface area than cuboidal cells. Alternatively, the changes observed may be due other factors such as increased secretion of intraluminal fluid induced by hyperoxia resulting in enlargement of the airways and thinning of the epithelium $(18,19)$.

This study is subject to several limitations. Estimation the relative role of apoptosis and proliferation in modulating the architecture of cultured fetal lung tissue exposed to high $\mathrm{PO}_{2}$ is difficult. The apoptosis indices for cultured fetal lungs reported in the present study are similar to those reported for cultured fetal lung tissue by Scavo et al. (20). However, to accurately estimate the loss in cell mass in fetal lungs tissue over time, it is necessary to determine the apoptotic cell clearance rate in addition to the apoptotic cell index. Thus, it is possible that differences in the apoptosis indices in $\mathrm{d} 1$ normoxia-exposed and hyperoxia-exposed fetal lung explants may be due to differences in the clearance rate of apoptotic cells. In addition, the cell proliferation index may not accurately measure changes in cell mass. We used Ki67 as a marker of cell proliferation (21). This nuclear antigen is expressed during all phases of the cell cycle except G0 (22). Thus, it is possible that cells positively staining for this antigen had not divided but were arrested in another phase of 
the cell cycle. Finally, although fetal tissues are exposed to lower oxygen tensions in utero, we opted to study fetal lung explants exposed to normoxia and hyperoxia because we were interested in the morphologic changes that occur when fetal lungs were exposed to postnatal life. We are aware of the range of gestational ages of the tissues studied, but are clearly limited by the availability of tissues.

The effects of hyperoxia in other reported studies appear to be dependent on the methodology used. Human and other animal studies suggest that cellular proliferation decreases in the interstitium but increases in the epithelium as gestation progresses. Hyperoxia exposure appears to decrease pulmonary cell proliferation rates in premature baboons and term mice in vivo $(23,24)$, but, in contrast, explants from term rats cultured in serum-free conditions exhibit no alteration in epithelial proliferation, and interstitial proliferation rates are increased with hyperoxia (25). Explant cultures are likely to differ from in vivo experiments in which blood inflammatory cells are likely to influence the outcomes.

The presence of serum in explant culture is not universally used. The hormones in serum-supplemented media have been shown to promote type II cell maturation during culture (26), and in the absence of serum-related factors, the natural pathway for cells to take is that of apoptosis (27). This may explain the regression of interstitium seen in other models, which have relied on serum-free media when culture has occurred in $21 \%$ oxygen $(20,28-30)$.

Culture of fetal human explants facilitates the study of lung in a blood-free system, allowing one to focus on the effects of local oxygen tension rather than systemic responses to hyperoxia and inflammation. The diffusion of oxygen through tissue follows a gradient, implying the surface of the specimens has a higher tension than within the core of the tissue (31). This phenomenon is difficult to eradicate in organ culture systems but also exists to a lesser degree in the developing in vivo lung. For this reason, we elected to compare high-power fields from the edge of the tissue circumferences, enabling valid comparisons between hyperoxic and normoxic environments.

Despite the study limitations, the architectural changes associated with culture in hyperoxic conditions were consistent, marked, and unequivocally linked to oxygen partial pressure. Whether the increase in inspired oxygen partial pressure after birth initiates changes in lung architecture in term and preterm neonates is not known. Evidence from studies performed in vitro shows that cell growth and death are regulated by (de-)activation of oxygen-sensitive proteins and genes. These include some members of the cyclindependent kinase family of cell-cycle regulatory proteins (32) and hypoxia-inducible factor 1 (33). Additional factors such as heme oxygenase-1 (34) are known to regulate activation of signal transduction pathways linked with cell proliferation and cell cycle arrest. As expected, VEGF mRNA decreased with hyperoxia exposure of the explants. This hypoxia-inducible growth factor is thought to play a role in vascularization of the embryonic lung (35), and expression has been shown to be regulated by oxygen tension in both newborn lung (36) and explant cultures (37). Absence of VEGF may provide an explanation for the "pruning" of vessels in the hyperoxiaexposed interstitium.

Other studies have shown that changes in oxygen partial pressure can also modulate the activity of genes and proteins that control cell function, including ion channels that control secretion of water out of cells $(18,19)$. Activation and/or increased expression of such ion channels may be relevant to the present fetal organ culture model because airway dilatation in hyperoxia-exposed explants may also involve secretion of fluid into airway lumina. Investigating the activation and expression of oxygen-sensitive genes and proteins may provide some understanding of the molecular mechanisms by which changes in $\mathrm{PO}_{2}$ lead to changes in the growth and function of cells in pseudoglandular stage cultured fetal human lungs explants. We plan to investigate these mechanisms in future experiments together with the effect of therapeutic interventions.

In summary, this study has demonstrated that exposure of fetal human lung explants to hyperoxia resulted in enlarged airways, a reduction of the interstitial compartment, decreased pulmonary blood vessels, a significantly smaller distance between airways and pulmonary blood vessels, and a flatter airway epithelium. These observations may largely be explained by differential apoptotic and proliferative responses between the epithelium and the interstitium to changes in environmental oxygen tensions.

Acknowledgments. We thank Drs. Alison Hislop and Susan Hall for their useful comments and suggestions.

\section{REFERENCES}

1. Pandya HC, Kotecha S 2001 Chronic lung disease of prematurity: clinical and pathophysiological correlates. Monaldi Arch Chest Dis 56:270-275

2. Husain AN, Siddiqui NH, Stocker JT 1998 Pathology of arrested acinar development in postsurfactant bronchopulmonary dysplasia. Hum Pathol 29:710-717

3. Margraf LR, Tomashefski JF Jr, Bruce MC, Dahms BB 1991 Morphometric analysis of the lung in bronchopulmonary dysplasia. Am Rev Respir Dis 143:391-400

4. Kotecha S, Wilson L, Wangoo A, Silverman M, Shaw RJ 1996 Increase in interleukin (IL)-1 beta and IL-6 in bronchoalveolar lavage fluid obtained from infants with chronic lung disease of prematurity. Pediatr Res 40:250-256

5. Kotecha S, Chan B, Azam N, Silverman M, Shaw RJ 1995 Increase in interleukin-8 and soluble intercellular adhesion molecule-1 in bronchoalveolar lavage fluid from premature infants who develop chronic lung disease. Arch Dis Child Fetal Neonatal Ed 72:F90-F96

6. Thibeault DW, Truog WE, Ekekezie II 2003 Acinar arterial changes with chronic lung disease of prematurity in the surfactant era. Pediatr Pulmonol 36:482-489

7. Kotecha S 2000 Lung growth: implications for the newborn infant. Arch Dis Child Fetal Neonatal Ed 82:F69-F74

8. Saugstad OD 1997 Bronchopulmonary dysplasia and oxidative stress: are we closer to an understanding of the pathogenesis of BPD? Acta Paediatr 86:1277-1282

9. Bonikos DS, Bensch KG, Ludwin SK, Northway WH Jr 1975 Oxygen toxicity in the newborn. The effect of prolonged 100 per cent $\mathrm{O} 2$ exposure on the lungs of newborn mice. Lab Invest 32:619-635

10. Janssen YM, Van Houten B, Borm PJ, Mossman BT 1993 Cell and tissue responses to oxidative damage. Lab Invest 69:261-274

11. Pandya HC, Snetkov VA, Twort CH, Ward JP, Hirst SJ 2002 Oxygen regulates mitogen-stimulated proliferation of fetal human airway smooth muscle cells. Am J Physiol Lung Cell Mol Physiol 283:L1220-L1230

12. Iwai K, Hieda Y, Nakanishi Y 1998 Effects of mesenchyme on epithelial tissue architecture revealed by tissue recombination experiments between the submandibular gland and lung of embryonic mice. Dev Growth Differ 40:327-334

13. Shannon JM, Gebb SA, Nielsen LD 1999 Induction of alveolar type II cell differentiation in embryonic tracheal epithelium in mesenchyme-free culture. Development $126: 1675-1688$

14. Kling DE, Lorenzo HK, Trbovich AM, Kinane TB, Donahoe PK, Schnitzer JJ 2002 MEK-1/2 inhibition reduces branching morphogenesis and causes mesenchymal cell apoptosis in fetal rat lungs. Am J Physiol Lung Cell Mol Physiol 282:L370-L378

15. McCray PB Jr., Bettencourt JD, Bastacky J 1992 Developing bronchopulmonary epithelium of the human fetus secretes fluid. Am J Physiol 262:L270-L279 
16. Machelon V, Nome F 1999 Cellular distribution and relative amounts of vascular endothelium growth factor mRNA in granulosa cells from human preovulatory follicles. Eur Cytokine Netw 10:393-402

17. Snyder JM, Johnston JM, Mendelson CR 1981 Differentiation of type II cells of human fetal lung in vitro. Cell Tissue Res 220:17-25

18. Charafeddine L, D’Angio CT, Richards JL, Stripp BR, Finkelstein JN, Orlowski CC, LoMonaco MB, Paxhia A, Ryan RM 1999 Hyperoxia increases keratinocyte growth factor mRNA expression in neonatal rabbit lung. Am J Physiol 276:L105-L113

19. Graeff RW, Wang G, McCray PB Jr 1999 KGF and FGF-10 stimulate liquid secretion in human fetal lung. Pediatr Res 46:523-529

20. Scavo LM, Ertsey R, Chapin CJ, Allen L, Kitterman JA 1998 Apoptosis in the development of rat and human fetal lungs. Am J Respir Cell Mol Biol 18:21-31

21. Schluter C, Duchrow M, Wohlenberg C, Becker MH, Key G, Flad HD, Gerdes J 1993 The cell proliferation-associated antigen of antibody Ki67: a very large, ubiquitous nuclear protein with numerous repeated elements, representing a new kind of cell cycle-maintaining proteins. J Cell Biol 123:513-522

22. Gerdes J, Lemke H, Baisch H, Wacker HH, Schwab U, Stein H 1984 Cell cycle analysis of a cell proliferation-associated human nuclear antigen defined by the monoclonal antibody Ki-67. J Immunol 133:1710-1715

23. Maniscalco WM, Watkins RH, O'Reilly MA, Shea CP 2002 Increased epithelial cell proliferation in very premature baboons with chronic lung disease. Am J Physiol Lung Cell Mol Physiol 283:L991-L1001

24. Warner BB, Stuart LA, Papes RA, Wispe JR 1998 Functional and pathological effects of prolonged hyperoxia in neonatal mice. Am J Physiol 275:L110-L117

25. Chetty A, Nielsen HC 2002 Regulation of cell proliferation by insulin-like growth factor 1 in hyperoxia-exposed neonatal rat lung. Mol Genet Metab 75:265-275

26. Tanswell AK, Joneja MG, Possmayer F, Harding P 1984 Differentiation-arrested rat fetal lung in primary monolayer cell culture. IV. Paradoxical effect of a "fetal" pO2 on precursor incorporation into phospholipids and hormone responsiveness. In Vitro 20:635-641
27. Raff MC 1992 Social controls on cell survival and cell death. Nature 356:397-400

28. Cossar D, Bell J, Lang M, Hume R 1993 Development of human fetal lung in organ culture compared with in utero ontogeny. In Vitro Cell Dev Biol Anim 29A:319-324

29. Hume R, Bell J, Cossar D, Giles M, Hallas A, Kelly R 1996 Differential release of prostaglandins by organ cultures of human fetal trachea and lung. In Vitro Cell Dev Biol Anim 32:24-29

30. Acarregui MJ, Brown JJ, Mallampalli RK 1995 Oxygen modulates surfactant protein mRNA expression and phospholipid production in human fetal lung in vitro. Am J Physiol 268:L818-L825

31. Gassmann M, Fandrey J, Bichet S, Wartenberg M, Marti HH, Bauer C, Wenger RH, Acker H 1996 Oxygen supply and oxygen-dependent gene expression in differentiating embryonic stem cells. Proc Natl Acad Sci U S A 93:2867-2872

32. McGrath SA 1998 Induction of p21WAF/CIP1 during hyperoxia. Am J Respir Cell Mol Biol 18:179-187

33. Lee JW, Bae SH, Jeong JW, Kim SH, Kim KW 2004 Hypoxia-inducible factor-1 (HIF-1) alpha: its protein stability and biological functions. Exp Mol Med 36:1-12

34. Duckers HJ, Boehm M, True AL, Yet SF, San H, Park JL, Clinton Webb R, Lee ME, Nabel GJ, Nabel EG 2001 Heme oxygenase-1 protects against vascular constriction and proliferation. Nat Med 7:693-698

35. Healy AM, Morgenthau L, Zhu X, Farber HW, Cardoso WV 2000 VEGF is deposited in the subepithelial matrix at the leading edge of branching airways and stimulates neovascularization in the murine embryonic lung. Dev Dyn 219:341-352

36. Maniscalco WM, Watkins RH, D’Angio CT, Ryan RM 1997 Hyperoxic injury decreases alveolar epithelial cell expression of vascular endothelial growth factor (VEGF) in neonatal rabbit lung. Am J Respir Cell Mol Biol 16:557-567

37. Acarregui MJ, Penisten ST, Goss KL, Ramirez K, Snyder JM 1999 Vascular endothelial growth factor gene expression in human fetal lung in vitro. Am J Respir Cell Mol Biol 20:14-23 